own words, even at the risk of being considered prodigal of quotations, because the conclusion arrived at from his experience, his desire for improvement in practice, and his dependence on Providence for the success of means judiciously employed, can scarcely be more briefly or more forcibly expressed. "I am fully persuaded, after a long life and much experifence, that the more simple methods of cure, uulike the elegant technicalities of certain learned men, are generally more grateful to the stomach, more conducive to the restoration of health, and are more frequently accompanied with the divine blessing, than a pompous farrago of medicines, however much a manifold authority, new or old, may militate against this opinion or contradict the simple truth." The method of prescribing, at the period in which Dr. Harris practised, and before his time, was so contrary to the simple plan he advised, and consisted of such an incongruous mixture of multifarious ingredients, that it was not likely he should live to see old prejudices surmounted, and bis plan generally followed; indeed, for many years after his death, the art of prescribing remained complicated and indefinite, and it was left for the present generation to separate the good from the bad,-to choose the former and reject the latter,-to profit by the advanced state of botanical and chemical knowledge, itand thereby to contribute materially to the alleriation of the various ills of mortality.

(To be continued.)

\section{CASE OF POISONING BY ARSENIC,}

PRESENTING BOME PECULIARITIES.

By M. M. DE Bartolome, M.D., Sheffield.

(Read before the Sheffield Medical Society, Oct. 2nd, 1818.)

The destruction of human life by the agency of poison has of late years been most lamentably on the increase, and although the improved und daily improving state of chemical science fortunately enables us to ascertain with ease and certainty, (at least in the case of mineral poisons,) the precise poison employed, yet cases are now and then met with presenting cyrain anomalies, either in the post-mortem appearances, or in the results of the analysis by which we endeavour to detect the poisoning agent employed. Conceiving that it is the duty of every medical man to lay any such cases which may fall within the scope of his observation before the profession generally, I am induced to bring before this Society the following case, and in doing so, I shall endeavour to call your attention to those points of resemblance to, or deviation from, the usual routine of similar cases :-

The subject of the melancholy investigation which I am about detailing, was Mary S., a scissor-burnisher. It appears from the evidence at the inquest, that an improper intimacy had for some time existed between her and an apprentice, who was frequently employed in the same room with her, the result of which was her becoming pregnant; and it likevise appears that she had frequently expressed her determination never to become a motber, although both the lad by whom she was "enceinte," and another man with whom she "kept company," had often expressed a willingness to marry her.

On Wednesday, August 16th, 1848, she left her home about 7 p.m., and returned about 9 p.m., during which absence it is supposed she procured the poison, either by buying it herself, with a view to self-destruction, or by having it from some one with the intention of inducing abortion. On this point we are completely in the dark, for although the police enquired at more than fifty druggists' shops in the town, not the slightest information could be gathered by them, either to establish the fact of her having bought the poison herself, or tending to criminate others. On her return home she complained of being very ill, and her mother made her some gruel, into which it is presumed the poison was put by herself. On the following day, as she continued very unwell, her mother gave her some Epsom salts, and again on the Friday, her suffering still continuing, her mother gave her some castor oil; but no one having any suspicions of the real state of matters, no medical man was sent for until about ten minutes before her death, which occurred on Friday, August 15 th, at 8 p.m., although romiting and purging had existed, almost without intermission, for upwards of twenty.four hours. Mr. Martin having been sent for, and being from home at the time, Mr. Newton, his assistant, saw her, as I have stated, about ten minutes before her death, which actually took place while he was still in the house.

On Sunday, August 20th, 1848, at 9, a.m., thirtysix hours after death, the body was inspected by $\mathbf{M r}$. Martin and myself, assisted by Mr. Newton. The body externally presented no marks of violence, but it was much ecchymosed from gravitation. About midway between the pubis and nmbilicus a tumour was felt, like a truncated cone, which, on removing the abdominal parieties, proved to be the uterus, evidently in an impregnated state. The head externally presented nothing abnormal. On the surface of the brain there was a good deal of venous congestion, and its substance presented a much greater number of bloody points than natural. The ventricles contained about half an ounce of serum each. The cortical matter of the cerebellum was more injected than that of the cerebrum; the medullary less so. Thorax:-The right lung was perfectly healthy and crepitated freely; the pleura on the same side was healthy; the left lung was likewise healthy, and crepitated freely, but the lefo pleura was adherent all over its surface. The heart was rather larger than natural, particularly the right side; otherwise apparently healthy; on cutting into it, however, its substance was found very flabby, and its cavities filled with coagula-particularly those of the right side. The valres were all perfectly healthy. Abdomen:-The peritoneal coat covering the fundus uteri was more injected than natural, and in some places ecchymosed, giving the viscus a mottled appearance. The fundus uteri, at its broadest part, was about seven inches in diameter, and from the fundus to the os uteri the distance was nine inches. On cutting through the fundus uteri an ecchymosed 
patch, about three inches by one and-a-half inch, was seen between the membranes on the middle of the anterior surface, and another similar patch lower down. The placenta extended across the cervix uteri, and was partially separated. The membranes enclosed a foetus, eleven inches long, and apparently from five to six months old. The stomach and bowels were distended with gas; the peritoneal coat over the large curvature of the stomach, and on the right side, presented many congested patches of various sizes, from half an inch to an inch in diameter. These patches nearly coalesced, so as to give the stomach the appearance of general external congestion over an extent of about four inches by two. The large intestines were healthy externally, but the small were rather more injected than natural. The liver was very pale, and rather mottled; its edges attenuated and condensed. The right kidney was gorged with blood; the left not so much congested. The stomach and its contents, as well as the contents of the intestine, were removed for examination. The intestines in. ternally were, generally speaking, healthy, but rather exsanguine, except here and there a slight ecchymosed patch of no importance. In almost every portion of the intestines a yellow gritty matter was found in considerable quantity, and perfectly detached. Stomach internally:-The mucous membrane pre. sented several highly congested patches, some of which corresponded with the congestion observed on the peritoneal coat, whilst others were independent of it, but all of them appeared upon the pyloric end of the stomach. In no part of its surface was the mucous membrane ulcerated. Along the lesser curvature of the stomach a yellow gritty matter similar to that seen in the intestines was found in considerable quantity. Su far as we could judge by the eye there were at least twenty grains of this substance altogether. It presented the colour and general appear. ance of sulphuret of arsenic, and was of an homogeneous colour.

This substance, on being analysed by us, proved to be the sulphuret of arsenic. On its being simply heated in a tabe, with charcoal and carbonate of soda deprived of its water of crystallization, a metallic ring was produced, presenting all the characters of metallic arsenic. Another portion heated with the same flux, in a tube open at both ends, sublimated into arsenious acid, which, on being dissolved in boiling distilled water, gave with the liquid tests the most conclusive evidence of the presence of arsenic. Another portion of this yellow matter was boiled in distilled water, filtered, and the tests applied to it, but withont any satisfactory result, evenafter the addition of caustic ammonia. A portion of the liquid contents of the stomach and intestines was then filtered and the tests applied as before, without detecting arsenic. Another portion was boiled in diluted muriatic acid, and properly prepared animal charcoal, and then filtered. This was divided into two portions-one was simply tested as usual by all theliquid tests, and to the other caustic ammonia was first added and thon tested; but in neither case was the least trace of arsenic found.
Some of the charcoal left upon the filter was next dried and put into a tube with desiccated carbonate of soda, and on the application of heat the metallio ring and likewise a ring of arsenious acid were produced; and on the latter being boiled in distilled water, and tested in the usual way, the most satisfactory evidence of the presence of arsenic was obtained. A small quan. tity of the same charcoal was then treatel with caustic ammonia, and on being tested produced the same results.

I may here mention, that the tests used in the different processes detailed above were-AmmonioNitrate of Silver; Ammonio-Sulphate of Copper; Sulphuretted Hydrogen; Lime Water; Bichromate of Potass.

From a careful consideration of the foregoing facts I am decidly of opinion that the form of arsenic taken was the sulphuret, at all events that it was not arsenious acid; and to this conclusion I am led, both by the results of the chemical analysis carefully performed, and by the post-mortem appearances. I am further inclined to think that it was a native and not an artificial sulphnret, because of the length of time the patient lived after taking it. Native sulphuret of arsenic is nearly, if not quite, insoluble in water, whilst the artificial sulphuret generally contains as we shall presently see, a considerable portion of arsenious acid.

The results of the chemical analysis clearly proved that the liquid contents of the stomach and intestines contained no arsenic in a soluble form, but merely held in mechanical suspension; and hence we find that although the solid matter left upon the filter gave both by reduction and by the liquid tests after solution in ammonia, convincing proofs of the presence of arsenic, not the slightest trace of this metal could be detected in the filtered fluid. Again, the gritty yellow matter so abundantly found in the stomach and intestines, was of an homogeneous yellow colour; and we can scarcely imagine a state of the digestive organs so totally depraved as to produce a quantity of sulphu. retted hydrogen sufficient to change the whole of the arsenious acid taken, into the sulphuret of arsenic, in the short space of tro days.

Christison, speaking on this subject, 8ays, "Sulphuret of aitsenic sometimes exists in small quantity in the stomach although the poison was given in the form of oxide." And in the account of a case examined by Professor Traill of Edinburgh, five months after interment, we are told, "the cohtents of the stomach consisted of a considerable quantity of yellow sandy matter, of the consistehce of paste. The contents and adhering crusts were found to consist chiefly of oxide of arsenic partially converted into sulphuret. If five wionths were not sufficient time to convert the whole of the arsenious acid into sulphuret, and the crusts' were only partially so converted, we cannot, I think, snppose that two days could by any possibility be sufficient to perfectly effect the change and leave no restige of the original arsenious acid.

The appearances found after death seem, in $\mathrm{my}$ opinion, to lead to the same conclusion, - - viz., that the metal was not taken in the form of oxide, for they 
were by no means such as are generally found in cases of poisoning by arsenious acid; and indeed, some of them are diametrically opposed to those described by some authors; I shall, therefore, claim your indulgence while I briefly notice some of the most remarkable, as nearly as possible, in the order in which we observed them. is

The peritoneal covering of the stomach, as already stated, was found considerably congested - an appear. ance seldom found according to Christison, for he says, "It is singular that, however severe the irhatumation of the inner membrane of the stomach may be, inflam. matory redness of the peritoneal coat is seldom found; yet inflammatory vascularity does occur sometimes on the peritoneal coat."

The mucous membrane has been represented by various authors as being in such cases soft, brittle, and easily separable. In the instance at present under consideration, the contrary was the case, for this membrane was quite as firm as usual-a state which certainly tends to strengthen the supposition that the poison taken was not arsenious acid; for it is, I think, very improbable that any arsenious acid could have remained for two days adhering to the mucous coat of thes bitomach without causing a more violent degree of infltwation than was obserred in this case, and withont inducing the more or less extensive destruction of the macous membrane.

Speaking of the effects of arsenions acid upon the intestines, Christison says, "It is a curious fact, that the rectum is sometimes much inflamed, though the colon, and more particularly the small intestines, are not.." Dr. Male and Dr. Baillie have recorded cases in which the rectum was redder than the stomach itself, and the anus ulcerated, and even in a state of gangrene. Bachmann and others have stated that they have found the external parts of generation much congested, and in females even in a state of gangrene. In the case of Mary S., the contrary was observed. The small intestines alone were more injected than natural, whilst the large intestines, the anus, and the external parts of generation, were perfectly healthy.

Pyl relates a case in which the inside of the uterns and Fallopian tubes was inflamed, and this certainly agrees with the condition in which those parts were found in the present case.

The lining membrane of the heart is represented by some authors as being unusually red, and Brudiẹ and Wildberg assert that the blood of animals killed by arsenic is commonly fluid, whilst, on the other hand, Wepfer, Sproegel, and Jaeger, state that it is black and semigelatinons. If our case is to decide between these authors, we must pronounce them all right and all wrong, because we found the blood contained within the heart coagulated, but rather florid than otheppisecertainly not black.

It may be urged by those gentlemen who may differ from me in opinion as to the form of arsenic taken in this instance, that the sulphurets of arsenic are not 80 easily procured as the arsenious acid itself, nor so likely to be known as poisons by the vulgar; bnt this objection loses mach of its force, when wo reppetuber that in the celebrated Bristol case, published by Dr. Symonds, it was proved at the trial, "that the poison used was artificial orpiment."

Dr. Duncan wet with an instance of an attempt to poison by mixing King's yellow with tea. Another case is related by Christison, in which King's yellow was intentionally taken in Edinburgh, and proved fatal in thirty-six bours; and another which occurred at Glasgow, in 1822, where a woman was tried for poison. ing her child with the same substance.

In the Bristol case death took place within a very few hours, and on a sample of the poison obtained at the same druggist's shop where the fatal dose had been bought, being analysed, it was found to contain no less than 79.100 of arsenious acid. This was probably the case in the instance given by Christison, as occurring in Edinburgh, in which death took place in thirtysix hours.

In conclusion, I will merely mention that Hahnemann, who is generally considered as having over-estimated the solubility of the sulphurets of arsenic, states that native orpiment is soluble in 5,000 parts of boiling water, and the artificial in 600 , a difference in solubility which could only be accounted for by the fact already named, that the artificial orpiment contains a large proportion of arsenious acid, whioh is soluble in 16 parts of boiling, or in 100 parts of cold, water. It is now, however, pretty generally supposed, that Hahnemann was mistaken, and that the sulphuret is not dissolved, but decomposed by the water, which, by giving it its oxygen, converts it into arsenious acid, the hydrogen and the sulphur set free by this double decomposition, farming sulphuretted hydrogen, which is then evolved.

I had almost forgotten to call your attention to the enormous quantity of the poison which this unfortunate girl must have taken, since, although romiting and purging had continued almost without intermission for upwards of twenty-four hours before death, so large a quantity as twenty grains was nerertheless found in the alimentary canal.

\section{ON THE MINUTE ANATOMY OF THE} AIR-CEILLS.

TO THE BDITOR OF THE PROVINCIAL MEDICAL AND Sir, SURGICAL JOURNAL.

It is at present a disputed point in microsoopic anatomy, whether there exists any epithelium on the internal free surface of the air.cells of the lungs. In his interesting paper "On the Minute Structure of the Lungs," Mr. Rainey has confirmed the opinion that the ciliated epithelium does not extend farther than the point at which the bronchial tubes terminate abruptly in the intercellular passages, "after which the passages conducting the air continue in the same direction as the bronchial tubes, of inich they are the continuation, but without having any perceptible membranous.

- Medico-Chirurgical Trans., Vol. xxviii.,p, 581. 1845. 